\title{
Opening Up The Tools For Doing Science: The Case Of The Global Open Science Hardware Movement
}

\author{
Julieta Cecilia Arancio (CENIT-UNSAM $\left.{ }^{1}\right)$
}

\begin{abstract}
Open science hardware (OSH) is a term frequently used to refer to artifacts, but also to a practice, a discipline and a collective of people worldwide pushing for open access to the design of tools to produce scientific knowledge. The Global Open Science Hardware (GOSH) movement gathers actors from academia, education, the private sector and civil society advocating for OSH to be ubiquitous by 2025. This paper examines the GOSH movement's emergence and main features through the lens of transitions theory and the grassroots innovation movements framework. GOSH is here described embedded in the context of the wider open hardware movement and analyzed in terms of framings that inform it, spaces opened up for action and strategies developed to open them. It is expected that this approach provides insights on niche development in the particular case of transitions towards more plural and democratic sociotechnical systems.
\end{abstract}

Keywords. Open science, open hardware, grassroots innovation movements, sociotechnical transitions

\section{INTRODUCTION}

Since the late 2000s more and more people all over the world are modifying, tweaking and building artifacts from scratch for different purposes, and releasing the design files to the public domain (Anderson, 2012; Powell, 2012; Kuznetsov \& Paulos, 2010). They make use of 3D-printing technology, cheap electronic components, biomaterials and other digital fabrication tools (Fressoli \& Smith, 2015; Gibb, 2014; Delfanti, 2012).

Within this currently well-established "maker" or do-it-yourself movement (Nguyen, 2016), a particular subgroup of people making open tools for science, or open science hardware $(\mathrm{OSH})$, has gained ground during the last 5 years (Murillo, 2018; Pearce, 2017; Wylie et al, 2014).

The Global Open Science Hardware (GOSH) community aggregates actors from a diversity of backgrounds and expectations, with the common goal of making ubiquitous by 2025 open designs of tools for science (GOSH, 2018). Since its inception OSH has gained greater visibility and has received coverage in academic and non-academic press: new mentorship programs were created, OSH projects have received funding and universities have started seeing its benefits. After three global gatherings, the publication of a manifesto, a roadmap and an action plan, GOSH started decentralizing its activities in 2019 in what seems to be a tipping point. It is therefore worth analyzing the movement's emergence and main features at this stage, where the previously blurry institutional interface is becoming clearer.

The aim of this article is to report on research about GOSH's short history as a grassroots

\footnotetext{
${ }^{1}$ Centro de Investigaciones para la Transformación (CENIT) - Universidad Nacional de San Martín (UNSAM), Buenos Aires, Argentina.
} 
innovation movement. The analytic framework is introduced in Section 2 and the methods adopted in Section 3. In turn, Section 4 describes GOSH's broader context, focusing on enablers and opportunities for the emergence of OSH. Section 5 presents the main actors and framings that inform the movement and shape its collective action. Section 6 continues with a characterization of the different spaces that GOSH practitioners have opened up for OSH development and, in section 7, the strategies they use to do it. Section 8 speculates about the alternative futures we could expect, learning from GOSH's recent history and the experience of other grassroots innovation movements.

\section{ANALYTIC FRAMEWORK}

In this paper GOSH is analyzed through the lens of the grassroots innovation movements (GIM) framework (Smith et al, 2017; Hess, 2007). GIM combines concepts from sociotechnical transitions theory and social movements literature to address the particular case of bottom-up knowledge-production civic movements. It also incorporates the concept of pathways developed by the STEPS Centre (Leach et al, 2010) to answer the question of how these particular innovation niches can contribute to alternative development routes (Hess, 2007; Smith, 2006).

GIM is a powerful framework to understand how innovation can emerge outside traditionally studied settings like the firm or research institutions; GIM promote social change by developing alternative or new forms of material culture (Hess, 2005). This is applicable to the case of GOSH, a heterogeneous collective with a clear call for social change, producing knowledge and technology outside traditional innovation circuits. These claims being politically explicit, power dynamics constitute an important part of the analysis: the social movements component of GIM illuminates this aspect.

The transitions component of GIM gives it a systems perspective, useful to analyze change dynamics as an interplay of multiple factors in the sociotechnical configuration. It is a co-evolutionary, systemic approach that understands sociotechnical change as the result of interactions between multiple levels in the sociotechnical system (Geels, 2019; Geels 2002): the innovation niche or GIM, the regime (or status quo, the established way of work) and the context. Strategic niches, or those with potential for fostering change, should be able to (i) articulate their expectations and visions in a robust and specific way, (ii) build deep and broad social networks, (iii) count with key intermediaries to exchange lessons and (iv) favour secondary learning in key areas, adapting their expectations and actions accordingly. The systemic approach turns out to be useful for studying a movement like GOSH, aiming to transform deeply rooted practices at the systems level.

Combining these approaches, GIM framework proposes to analyze four complementary dimensions (Smith et al, 2017): i) Context, or the historical circumstances in which GIM emerge; ii) Framings, or shared meanings, interpretations and narratives that hold the movement together and orientate its activities (Snow et al., 1986); iii) Spaces, or the collection of sites and arenas - physical, institutional, organizational and cognitive - where rules are different from the regime (Kemp et al., 1998; Seyfang and Smith, 2007) and allow GIM to actively open up material activity; iv) Strategies, or how these spaces are opened up in terms of the ability to generate networks and intermediaries, the repertoires of action or forms of organization developed to open spaces (Tilly, 2008) and the mobilization of 
resources (McCarthy \& Zald, 1977), both material and non-material (Oberschall, 1973).

\section{METHODS}

Thirteen semi-structured interviews were conducted with GOSH actors during late 2018 and early 2019, including participants of the three global gatherings, organizers and referents from North America, Africa, Europe and Latin America. This material was complemented with press articles, public community documents, data from the online GOSH forum and social media, plus participatory observation notes.

The analytical categories were embedded in the questionnaire following a chronological approach, intended to reconstruct the experiences of the interviewees at different stages of their participation. Following the principles of Grounded Theory (Glaser \& Strauss, 1967; Thornberg \& Charmaz, 2014) a first open coding process was applied followed by focused and theoretical coding. The analysis was performed using RQDA, an open source Computer Assisted Qualitative Data Analysis Software (CAQDAS). As a contribution to the community, an outreach article on GOSH's history was written and shared on the GOSH forum.

\section{CONTEXT - EMERGENCE OF THE OSH MOVEMENT}

Since the early 2000s a much wider spectrum of the public started tinkering with electronics, boosted by the upsurge in 3D printing (Söderberg, 2013), the irruption of educational electronic platforms (Hertz, 2011) and the availability of low-cost electronic components. Emblematic projects include the RepRap 3D printer (de Brujin, 2010) and the Arduino board in 2005, based on its predecessor Wiring in 2003. The first edition of MAKE magazine reference for the maker community worldwide - and the rise of new business models like Adafruit or Sparkfun (2003) had significant impact in consolidating both a community and a market. Moreover, the increasing popularity of practices from the hacker community, with numerous new physical spaces for open innovation such as makerspaces and fablabs, facilitated access to digital fabrication tools for a wider audience (Maxigas, 2014).

Since these early initiatives, making open hardware has become more accessible. There have been initiatives pushing for an open source software "toolchain" for open hardware (Murillo, 2018; Serrano, 2017) to enable more users to design. New business models offering services of "design for manufacturing", to facilitate the process of moving forward from do-it-yourself prototypes to industrial products at scale.

The boom of do-it-yourself electronics, coupled with the emergence of online platforms where information and knowledge circulate freely, favoured the sharing of designs and aggregation of practitioners in communities (Benkler, 2006). Open Hardware (OH) as an encompassing concept was first defined in 2010 after the first open hardware summit (Open Source Hardware Association (OSHWA), 2012), shortly after the first open hardware license was created in 2007 (Ackermann, 2009), followed in 2008 by the CERN Open Hardware License (Ayass \& Serrano, 2012).

Open hardware for science builds on these opportunities: the combination of 3D-printed parts and cheap electronic boards reduces the costs of science tools by $90-99 \%$ in some cases, 
when compared to proprietary equipment with equal functionality (Pearce, 2014). Besides academic publications, designs are also shared through maker community platforms; improvements in accessibility have enabled citizen-scientists and scientists without engineering backgrounds to build science hardware.

Besides these infrastructure opportunities, ideas around citizen participation and science democratization have played an important role in the emergence of OSH. In the beginning of the 2010s two environmental disasters in Japan -Fukushima in 2011- and the US -DeepWater Horizon in 2010- exposed the lack of transparency and performance of governments for providing accurate, updated environmental information to the public (Figueroa, 2013; Dosemagen, 2020). The increased availability of low-cost tools, combined with this lack of response from the scientific and political spheres opened up a window of opportunity for new forms of grassroots knowledge production. Citizen science, defined since the 1990s but reinvigorated during this period, witnessed a growth of projects and platforms gathering citizens' efforts for data collection, in particular in the natural sciences. More recently, this paradigm of citizen-scientists as data collectors for research projects started to face some criticism, demanding more empowerment of non-academics in citizen science projects (Resnik, 2015). In the US, a wave of "civic technology" initiatives constituted a major trend around technology-enabled civic participation (Wylie et al, 2014), with emerging new practices of community-based science (Dosemagen, 2020; Liboiron, 2017; Wylie et al, 2017).

In the academic world, ideas from the open-science movement were gaining significant ground (Albornoz et al, 2018) and expanding to other domains besides open access and open data (Ballell, 2013; Hylén, 2006). Criticism of hidden power dynamics in open science practice has called for developing more inclusive and situated open science and science in general (Chan et al, 2019; Okune et al, 2018; Albornoz \& Chan, 2018, Nature Editorial, 2018). More recently, the increasing adoption of open-science strategies at the policy and institutional level lowered the entry level for open hardware discussions to happen within institutions.

This shift towards promoting more diverse, inclusive and participatory systems of knowledge production both within academia and civil society contextualizes the emergence of GOSH community. Most interviewees recall that OSH initiatives consisted of only a few isolated cases around 2010, but by 2015 the situation had changed completely. Projects multiplied in the most diverse contexts, with new initiatives appearing not only in the US or western Europe, but globally. This was the scenario when the conversations about creating an OSH community started taking place, in 2014 (Fig. 1). 


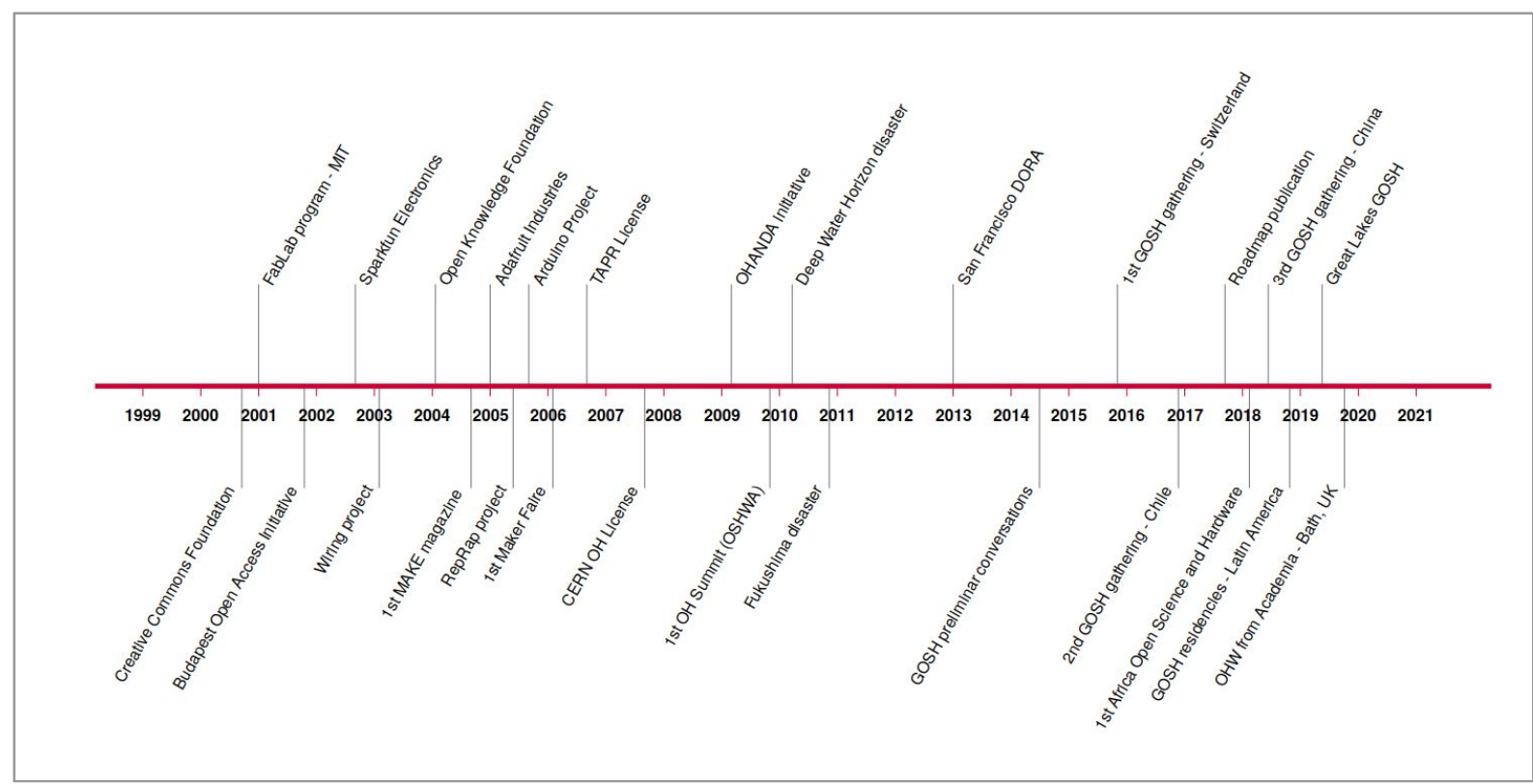

Figure 1: Timeline of events before the emergence of GOSH movement and its subsequent milestones (prepared by author based on interviews)

\section{FRAMINGS IN OSH}

GOSH founders and participants come from a wide variety of backgrounds, bringing in multiple ideas that converge in a main proposal stated in the GOSH manifesto. In the following subsections I describe these framings in terms of actors, their motivations, how they problematize the scenario and their visions for $\mathrm{OSH}$.

\section{Open science}

GOSH finds a significant number of its advocates in researchers within academia, mainly from the natural sciences. Originally with most researchers from Europe and the US, the distribution of the community intentionally changed after the first gathering in 2016, incorporating a significant number of participants from Africa and Latin America.

Academics in GOSH express that one of their main motivations to "go the open-source way" is a problem their predecessors were able to solve (von Hippel, 1976): tweak and adapt science tools to fit their very specific research needs. On the contrary, nowadays science tools are very difficult to fix, customize or fully inspect, due to patent restrictions and closed designs. This problematization is not far from the claims of other communities; however GOSH researchers understand that the barriers faced by users of science tools are particular and derive implications for the knowledge-production system and for society as a whole.

Not being able to access the blueprints of science hardware translates to important delays, costs for researchers and non-functional equipment piling up in university labs. Lock-in with vendors also represents a risk for research as companies may go out of business, drop a product line or lose specialized staff. Researchers identify the ultimate problem as a political one: "universities taking conservative approaches to intellectual property and patenting of innovations". 
OSH is envisioned as an enabler for "better science": designs can be inspected or peer reviewed transparently, avoiding duplication of efforts, getting better results, facilitating reproducibility and boosting academic careers for hardware builders. For research institutions and universities, it is argued that it represents an opportunity to save costs of repairing and buying equipment, seizing capacity of in-house personnel and increasing the quality of education. $\mathrm{OSH}$ is therefore presented as a more efficient and convenient way of doing science, for academics, students, institutions, companies, but ultimately for society, who would benefit from accelerated innovation in science and increased access to more and better knowledge around the world.

\section{Environmental justice, cognitive justice}

Environmental justice (EJ) - referring both to a social movement and a social sciences body of literature - deals with the question of how environmental benefits and damages are distributed within society, but more widely, of how communities can participate equally in environmental policy discussion, and their practices be recognized and valued (Agyeman et al, 2016). As a result, it calls for situating knowledge, practices and assessments, ensuring community recognition, and identifying barriers for participation. As a movement, it also holds a tradition of community-empowering practices through grassroots monitoring activities and knowledge-production processes (Roberts \& Toffolon-Weiss, 2001; UCC, 1987).

Closely related, cognitive justice calls for fraternity between forms of knowledge (Visvanathan 2001), claiming that our society privileges scientific knowledge over other forms of knowledge, which has undesirable social, economic and political consequences for communities (Mgbeoji, 2014).

Environmental justice and cognitive justice are frequent topics during GOSH meetings. Main actors include activists, NGOs, social scientists who see in OSH a powerful tool to foster change in society, achieving goals beyond academia and conventional ways of knowledge production. Their main motivation relies on the fact that the majority of the population, often subdued to environmental or other types of injustices, has restricted access to science tools, and therefore can not use them for their own research or education needs.

The existence of a closed, patented model for science tools is framed as the cause of concentration of technology design in small, privileged groups, creating a power asymmetry between tools creators and tools users. This asymmetry is problematized in different ways:

(a) Patents promote concentration of production, generating prohibitive costs and unavailability in some locations (e.g. imports restrictions);

(b) When technology is available, people are not able to effectively use it in a particular context or for a particular need, as it was not considered in design;

(c) When technology is available, it may not be accessible for a group of people, as they were not originally considered as users.

The closed model is therefore seen as reproducing systemic injustice(s). Lack of access to knowledge production tools for less represented sectors means more dominant - western, 
white, male, academic - knowledge produced, while drowning representation of non-hegemonic groups - low-resource, indigenous, women, non academic -. Related to the concept of undone science, as tools are only dominated by academics, governments or markets, the knowledge produced is only that which is interesting to those actors. As communities do not have the means to produce their own knowledge, their agendas are invisibilized.

These ideas have become a backbone ethos of GOSH. Pouring into the value-driven approach of the GOSH manifesto, they've become the foundation of the diversity strategies that all interviewees identify as what makes GOSH different from other communities in the technology and academic spaces.

\section{Appropriate technology and critical pedagogies}

The term 'appropriate technology' (AT), coined in the economic debates on development and assistance of the '60s (Smith et al, 2017), implied a set of shared characteristics: low-cost technologies, manufactured with local materials, employing local labour, small scale, without requiring high-level expertise or hegemonic education, collaborative or collective development, no use of patents or other intellectual property instruments. In some contexts, AT practitioners experimented with social participation for communities to define their own problems and experiment with their own solutions (Fressoli \& Arond, 2015). In South America in particular, AT ideas were influenced by the ideas of critical approaches to pedagogy, where education is understood as a tool for critical thinking and political activism (Freire 1973; Fals Borda, 1979).

Many participants in GOSH are educators and activists with a background in critical pedagogies. These actors problematize the closed science hardware system as an impediment for access to technology, favouring one-size-fits-all solutions that do not take into account the peculiarities of different contexts. Proprietary hardware is framed as one of the causes for asymmetrical north-south access to science and education, reinforcing technological dependence, constituting a major challenge for education, job insertion and development of local solutions to community problems.

The visions within this framing revolve around OSH as a way of democratizing science and technology, reducing the technology gap and contributing to development. Interviewees from African or Latin American communities, in concordance with previous studies showing connection with post-colonial and economic development issues (Kera, 2015), frame OSH as an avenue for underprivileged groups to be able to access, learn and use scientific tools for their own research, education and development needs.

\section{Hacker culture, trans-hacktivism}

The hacker movement, which informs most open and collaborative, peer-to-peer communities (Benkler, 2006), is commonly associated with an ethos based on liberal values such as freedom of information and expression, right to privacy, meritocracy and the power of individuals (Coleman, 2004; Levy, 1984). However the articulation of these concepts takes different shapes through interaction with other backgrounds, creating a set of related but different expressions around property, work and creativity (Coleman and Golub, 2008). One 
of this expressions, trans-hacktivism, presents intersecting points with previously described framings: it combines concepts from hacker culture with intersectional feminism and queer theory, critical pedagogy, technology decolonization and autonomism.

Artists, biohackers, trans-hacktivists in GOSH work in the continuum between craft, science and art, usually participating through hands-on workshops or performances during the gatherings. Many of them are also part of biohacking communities, like Hackteria or DIY Bio, or more institutional initiatives like the iGEM competition or the MIT Bio-summit.

Trans-hacktivists construct their main problematization around the dominance of one perspective embedded in technology design, its normative power and the consequences for individuals. Hegemony in technology design restricts possibilities for alternative visions of science and technology to emerge and grow. Usual topics include normalization of identities and bodies, loss of privacy due to surveillance capitalism, patriarcal expressions in technology.

Trans-hacktivists value collaboration instead of competition, self education, experimentation and failure as part of the experience of creating technology. Their vision frames OSH as an instrument towards developing autonomous infrastructures, decolonizing technology and decentralizing power.

\section{SPACES FOR OSH}

In the following subsections I describe four different spaces opened up by GOSH practitioners to develop their activities.

\section{Community science projects}

Community-based environmental monitoring - requiring low-cost tools that are easy to use and share, and transparent data-generation processes - is a fertile ground for OSH development. Some early examples include Public Lab, a non-profit running projects using $\mathrm{OSH}$ and community-organizing methods for environmental monitoring, and Safecast, a crowdfunded community science project that measures radiation using OSH. Both appeared in response to a lack of accurate official information on the impact of environmental disasters, and used OSH to build, learn and use low-cost-aerial photography kits and geiger counters respectively.

The biohacking community constitutes another significant space receptive to OSH. Biohacking, DIY bio or Garage Bio is defined as a movement of people conducting life sciences outside of traditional professional settings such as universities and corporate labs. Acquiring tools and equipment to do science outside academia is expensive and difficult, in particular as individuals. Hackeria and DIYBio are possibly the most important biohacking networks worldwide: communities that produce, test and put into practice artifacts developed by enthusiasts globally. Developments go from simple DIY incubators to PCR machines, including complete open sets for biology labs.

\section{Academic researchers}

The open-science movement focuses primarily on open data and open access to publications; 
the broader open-hardware movement hosts discussions oriented to the maker community. In the middle of both, GOSH attracted academics who were using or developing OSH marginally in their institutions, and didn't find their place in those related communities.

One of the spaces for OSH in academia is found amongst highly specialized research and engineering teams developing science tools or cutting-edge research. This group includes researchers who reverse-engineer proprietary tools, modify them and create their own versions using open licenses, as a way of fostering adoption and accelerating innovation. As an example, the Laboratory for Bio and Nano instrumentation at EPFL, Switzerland, has documented developments on open atomic force microscopy (AFM).

Another space was opened by researchers working in applied sciences with small budgets, where proprietary tools are not an option. OSH is a way to cover greater geographical areas or increase the number of samples analyzed with a limited budget. It is also a way to customize tools to highly specific contexts that were initially not considered by designers. Gorgas tracker, developed by the Health Innovation Lab from the Institute of Tropical Medicine 'Alexander von Humboldt', Perú, is an open-source tracker used to investigate Malaria and Human Mobility in the Peruvian Amazon. Based on an open-source phone, it allowed researchers to prototype and adjust the design to the extreme conditions of the Amazonian forest and the demands of indigenous communities involved in the study.

\section{Education and social innovation}

OSH gained spaces where educators with a critical view of traditional teaching methods started experimenting with open technologies for learning. This happened both inside and outside institutions of formal education.

Within schools and universities, usually oriented towards facilitating STEM education, OSH is used to develop challenge-based learning activities, accelerate experimenting and prototyping in the classroom. LEGO2NANO is a project started in 2013 with the support of the London Centre for Nanotechnology and the LEGO Foundation, when a group of $\mathrm{PhD}$ students from China and the UK took up the challenge of building an open, low-cost AFM. With the goal of bringing nanoscience to high-school classrooms, students were able to put together a working prototype built from LEGO, Arduino, cheap 3D-printable parts and consumer electronic components. The project inspired others worldwide, who started implementing OSH in the classroom (Heradio et al, 2018).

Another space was opened by numerous educational projects run by NGOs, communities and entrepreneurs around the world who started using OSH as a bridge between education and social innovation. Kharkana and the Tech Academy are extracurricular education projects in Nepal and Bangladesh respectively that promote STEM education through collaboration, experimentation and play. Their students come from different backgrounds; in the case of the Tech Academy, education is granted for free to students with families who can not pay for it. Both initiatives use a learning-by-doing approach, intended to foster creativity in students while they acquire digital skills, applying them to developing solutions for their local problems. Students' projects often participate in international innovation contests, many times related to the UN Sustainable Development Goals. 


\section{Artists}

Artists working in the interface of science and art use OSH tools in different domains: biomaterials and textiles, audiovisual experiences and even interspecies communications. OSH gained a space here as its rapid-prototyping methodology enables experimentation at low cost, available documentation allows artists to learn how tools work and data is produced, and because paywalled information becomes a real challenge to most artists, who are not affiliated to scientific institutions.

Interspecifics is a project born in Mexico that defines itself as a "nomadic multispecies collectivity experimenting in the intersection between art and science". It transforms electric signaling from different species into audible sounds. Not having any affiliation with a scientific institution, access to scientific publications is usually paywalled: the project relies entirely on openly available knowledge. As a way to give back, they completely documented their hardware and other developments in the open.

\section{STRATEGIES FOR OSH}

In this section we present some of the strategies GOSH develops in order to pursue its vision and open spaces for its activities, categorized into three main groups: networks and intermediaries, repertoires of action and mobilization of resources.

\section{Networks and intermediaries}

GOSH is a diverse network of networks with nodes in academia, civil-society organizations and the entrepreneurial world. This configuration includes non-profits, funding institutions, research institutes and universities, makerspaces, artists, social innovators and educators worldwide (Fig. 2).

The network acts as a platform for increasing visibility and communicating projects' and nodes' activities at the international level. These include presentations in academic and non-academic venues, press articles (Brazil, 2018), new residencies and gatherings announced via GOSH blog, projects promoted via the global community social media accounts. Regional gatherings usually make use of the global community channels to amplify their message through networks with differentiated audiences.

Besides internationalization and widening audiences, nodes within the GOSH network exchange information through key intermediaries. Lessons shared are technical but also organizational. Researchers from Germany have been invited to Chile to run workshops at universities, bringing not only hardware but also a reproducible methodology that can later be replicated, and modified, by local researchers. Talks, presentations, workshops or direct collaborations between projects are common. 


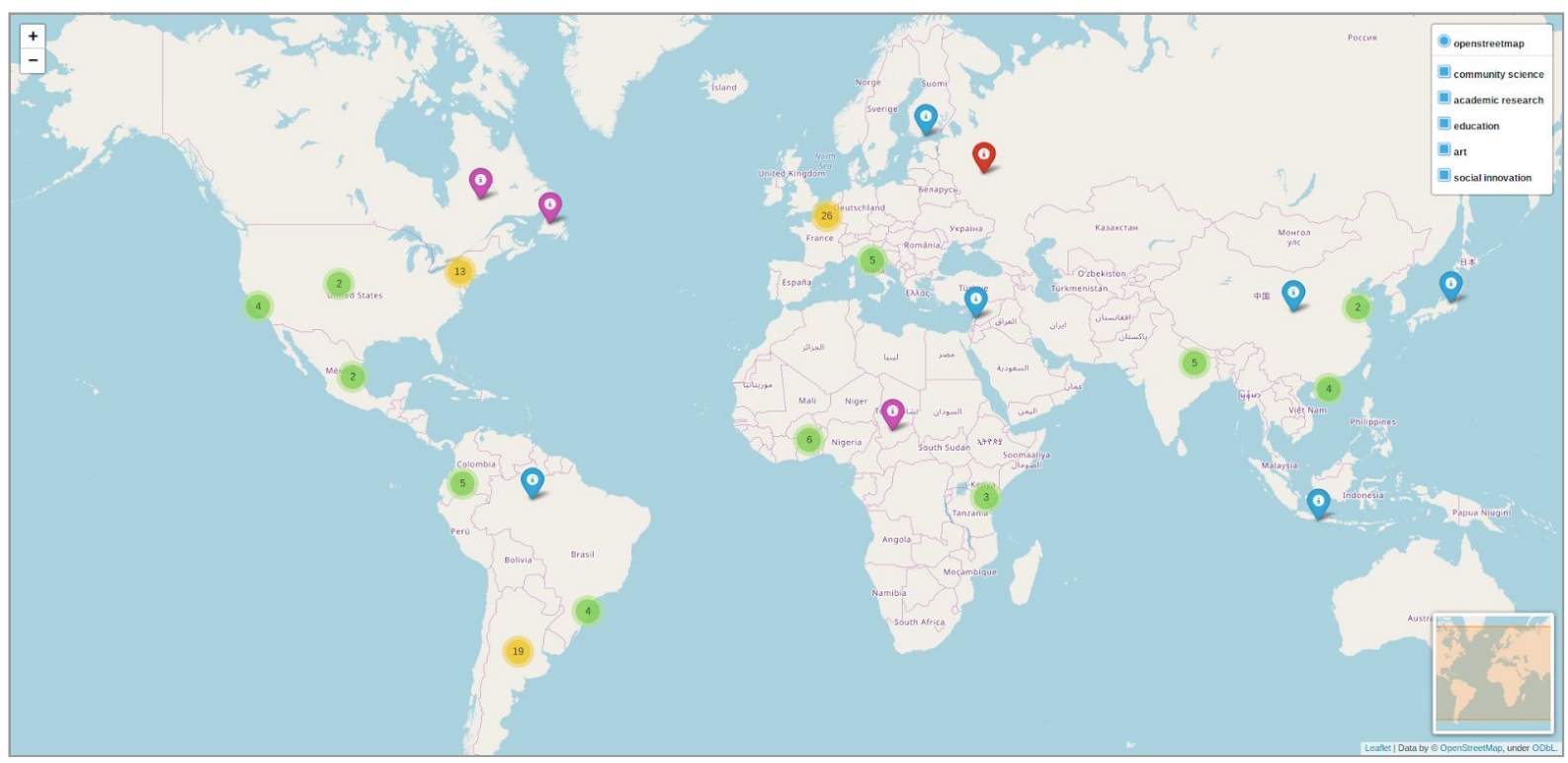

Figure 2. Distribution of GOSH initiatives worldwide categorized according to spaces (compiled by author based on public records and interviews, interactive version available).

\section{Repertoires of action}

The main strategy developed by GOSH during its first three years of life was organizing global gatherings. The meetings are used as an instrument to deliberate, learn, make and define the values, strategies and actions for the collective to move forward. Since the first meeting, each gathering was used as a starting point for elaborating collaborative strategy: the manifesto in 2016, the roadmap in 2017 and the action plan in 2018. The methods used for achieving it are openly documented, and replicated in the new instances of events emerging in different parts of the world.

The intentional mechanisms put in place to ensure diversity of participants during the gatherings can be considered a strategy in itself. Diversity allows the collective to have "representatives" from almost every area inputting their visions into GOSH. This turns GOSH into a deliberation space and reference, as can be seen in the growing requests for interviews from the press and appearance in other communities' documents.

Diversity also allows the community to "tailor" its message according to the audience, being able to frame OSH differently according to the context. Researchers actively promote OSH into broader Open Science conversations ('there is no open science without open science hardware'), activists promote the appropriate technology and democratization aspect, artists evoque its transparency and potential for developing autonomous infrastructures.

Another important component of the gathering strategy is the combination of material and reflexive activity. Seventy percent of the program is defined on demand during the gathering, combining hands-on workshops on building and using OSH with discussion sessions on topics chosen by the audience and instances of group deliberation. Different people occupy different roles according to their interests, contributing with their different perspectives. Results of community deliberation are translated into documents available online for collaboration, which amplifies the message online, acts as a legitimation strategy 
by enlarging the contributor base and is useful as a communication piece itself, promoting the movement's activity.

Promotion of impactful developments or 'use cases' constitutes another important strategy. The OpenFlexure microscope was created by academics from the University of Bath who developed a collaboration with academics and community organizers in Ghana. The tool has been completely replicated by the partners in Ghana using locally available materials, who are now using it as a method for easy, quick and low-cost detection of Malaria. These kinds of artifacts connect actors globally through powerful narratives, condensing values of the community and constituting effective communication pieces. The OpenFlexure microscope has been featured in mass media press, besides appearing in news from academic and community circles.

The definition of a research agenda on OSH and the creation of community publication venues is another strategy related not only to reflection on the movement activity but also to seek legitimacy within academic rules and demonstrate the superior performance of OSH versus proprietary equipment.

\section{Mobilization of resources}

Financial support has been mainly mobilized through access to grants from US-based foundations in the open-technologies space. The gatherings are free of charge for participants, although there is a suggested fee for contributing to cover other participants' costs. Financial support for GOSH activities in Latin America comes from grants from an Iberoamerican funding agency for science and technology. Africa OSH received personal funding from its organizers. Funding for project development also comes from crowdfunding activities, which also help gaining visibility.

As many participants of GOSH work at universities or community spaces, fablabs, community makerspaces and other venues are usually accessible to the community for low or no cost. Hardware materials, when not coming from grant money, are usually paid for or obtained through sponsorship from electronics suppliers.

In terms of non-material resources, GOSH is entirely run on volunteer work, on which it depends for different functions. Leadership, organization and communication skills are key resources for GOSH development, which have been mobilized mainly from GOSH participants that also happen to be community organizers. Technical skills are required for building hardware; these usually come from experts in the community that contribute to other projects through the GOSH forum online or directly participating as key intermediaries, transmitting lessons to other projects or connecting with other experts. Technical expertise is recognized through credit in designs or scientific articles.

Trust is another important resource mobilized mainly from original GOSH founders, which enables access to grants but also visibility through articles in the press and social media. Access to prestigious networks acts as a resource of legitimacy for the outside. Interviewees mention that 'serious' actors being involved in GOSH (important universities, non-profits, research institutions, researchers) contributes to supporting their daily work at their home institutions. 
Positioning GOSH as part of other movements mobilizes resources in terms of shared culture and knowledge: it attracts people from those communities, provides vocabulary and narratives, facilitates lessons and visibility. This strategy can be observed in academic press articles where GOSH is presented as a subgroup of the open-science movement, or when presenting to a more maker audience, as a branch of the maker movement. In terms of knowledge, e.g. business models of open-source software are taken as a point of departure to study potential business models for OSH.

The contact with the appropriate technology movement, feminist, post-colonial studies or environmental-justice movements are some examples of mobilization of historical tradition and ideology resources that help approaching specific actors at the local level, like agroecology initiatives and social movements in Latin America.

\section{DISCUSSION}

The analysis of GOSH as a grassroots innovation movement provides some basis for considering it a strategic niche with the potential for influencing the regime of patent-based scientific knowledge production.

GOSH's collective ideas, though informed by multiple and diverse actors, are clearly articulated in open, collaborative and living documents and are communicated to the outside world through independent but also massive media and press. This articulation has evolved and gained specificity through the years, as can be seen with the evolution of public documents on collective strategy: from the manifesto to the roadmap to a concrete action plan.

GOSH participants have the ability to build networks, which on one hand are broad: the collective is linked to actors in the local, regional and even international level; actors include practitioners but also companies, academic institutions, civil-society organizations. On the other hand, these networks are also deep: participants are able to mobilize different kinds of resources from them through a diversity of strategies. The presence of key intermediaries is evidenced by the multiple exchanges between participants, both for technical and organizational skills exchange.

The evolution of GOSH activity presents evidence of secondary learning, systematizing lessons and adapting their actions, expectations and strategies based on evidence. The decision to become a global movement after the first gathering came after a self-evaluation that pointed out the lack of diversity in participants; the decision to engage with more industry-related actors in the third gathering in China, in response to a perceived need from the participants in Chile and other discussion forums to scale their projects, the decision to decentralize activities in order to avoid burnout of key members of the movement during the last gathering; all of these show how actions in the movement are adaptive.

\section{Futures and open questions}

During 2019 there was no global GOSH gathering: participants started organizing more regional and local activities while the conversation of governance, sustainability and the 
future of the movement slowly started taking place. The analysis makes evident that framings informing GOSH are diverse and some of them are more radical in their demands than others. It also provides some material for understanding GOSH's current situation and speculate about possible futures. Going back to the concept of alternative pathways, how differently will these diverse ideas influence the regime?

Lessons learned from historical analysis of other grassroots innovation movements, though not transferable, can still provide some insights. In his study of the trajectory of the organic food production niche in the UK, Smith (2006) sheds light into the dialectic nature of niche-regime relationships. Diverse actors in the sociotechnical system appropriate some of the niche practices differently, leading to niche fragmentation, incremental innovation and renewed alternatives hosting more radical cores. Smith suggests policy should encourage this dual nature of niches, both radical and reforming.

As mentioned, some OSH practices are easier to be absorbed by institutions than others. How would this differential appropriation affect GOSH as a collective? We can picture a scenario, not too far away in time, where top university labs and research institutes are equipped with open science hardware, where design and engineering curricula includes open models of hardware production and fablabs or makerspaces turn into "tech support" and developing hubs for in-house researchers. Hardware is produced by companies who publish the designs online under open licenses. The benefits start showing in terms of coordination of research efforts, repairability and acceleration of innovations. However, designs are still difficult to replicate in some parts of the world where components are not available. As the new designs become a de-facto standard for research, maybe even certified, in poor countries researchers still depend on manufacturers, widening the knowledge gap. Documentation is published but is still unreadable for non-experts or non-English speakers, so inclusion of more diverse actors isn't happening. In this scenario of OSH becoming default, GOSH starts fragmenting. It can disappear if there is no one to embody the new demands; but the importance and key role of more radical framings related to appropriate technology, critical pedagogies and environmental justice in GOSH opens the possibility of reconfiguration: some participants move away, as their demands are satisfied; those who remain put the previously more radical claims in the center: OSH must not only be ubiquitous, it must be also accessible for everyone. The change in framing opens up new spaces and strategies to pursue the reconfigured goal.

Lessons learned also point out that more radical niches have to "prove" more important benefits in order to influence the regime, but that this is not a static process: how radical the niche is perceived to be and how important its benefits are, change with time and with the emergence of tensions in the regime. Which tensions in the regime can be framed as opportunities for OSH? Is it the context of a global COVID-19 pandemic, where the patented model of production leaves the world's hospitals and workers short of vital tools, a tension strong enough to open an opportunity?

Thinking again of a scenario with OSH as default, the designs of certified personal protective equipment (respirators, goggles, garments) and medical/laboratory equipment (ventilators, PCRs for tests, tools for vaccine research) are openly released - some suppliers are already doing it - and available online. Using these public specifications, industries that produce other similar goods can reorient their processes more easily to fulfill some of the demand. 
Fablabs and makerspaces can quickly grab PPE designs and start producing for their communities and local hospitals. Differently from now, makers don't have to reverse-engineer but can adapt already performant and safe designs, saving precious time in coordination and production, avoiding undesirable side-effects such as governments trying to homologate DIY designs. OSH as a default also means more laboratories can process samples for testing, access more equipment for working towards vaccines, and produce them faster.

Scientific data and knowledge are at the heart of most of the more complex challenges people and institutions face in the 21 st century. OSH is a young but growing movement that has the potential to transform the current way in which scientific knowledge and equipment are produced. The course OSH takes towards influencing the current way of doing science depends on many factors within the sociotechnical system: activists' strategies, context tensions, emergence of policy supporting OSH and new business models based on openness, the ability of institutions to adapt, cultural shifts in academic practice, public perception. The proposal of imagining possible near futures for OSH taking into account historic lessons is intended to promote reflection on strategies to foster change at these different levels, taking into account the new political configurations that will necessarily emerge in these new scenarios.

\section{REFERENCES}

Ackermann, J. R. (2009). Toward Open Source Hardware. University of Dayton Law Review, 34(2), 183. Available at https://web.tapr.org/Ackermann_Open_Source_Hardware_Article 2009.pdf

Agyeman, J., Schlosberg, D., Craven, L., \& Matthews, C. (2016). Trends and Directions in Environmental Justice: From Inequity to Everyday Life, Community, and Just Sustainabilities. Annual Review of Environment and Resources, 41(1), 321-340. https://doi.org/10.1146/annurev-environ-110615-090052

Albornoz, D., \& Chan, L. (2018). Power and Inequality in Open Science Discourses. IRIS - Revista de Informação, Memória e Tecnologia, 4(1), 70-79. Available at https://periodicos.ufpe.br/revistas/IRIS/article/view/238912/30639

Albornoz, D., Huang, M., Martin, I. M., Mateus, M., Touré, A. Y., \& Chan, L. (2018, June 15). Framing Power: Tracing Key Discourses in Open Science Policies. 22nd International Conference on Electronic Publishing. https://doi.org/10.4000/proceedings.elpub.2018.23

Anderson, C. (2012). MAKERS. The new industrial revolution. Crown Business.

Ayass, M., \& Serrano, J. (2012). The CERN Open Hardware Licence. International Free and Open Source Software Law Review, 71-78. https://doi.org/10.5033/ifosslr.v4i1.65

Ballell, L., Bates, R. H., Young, R. J., Alvarez-Gomez, D., Alvarez-Ruiz, E., Barroso, V., ... \& Lozano, S. (2013). Fueling open-source drug discovery: 177 small-molecule leads against tuberculosis. ChemMedChem, 8(2), 313-321. Available at: https://www.ncbi.nlm.nih.gov/pmc/articles/PMC3743164/

Benkler, Y. (2006). The wealth of networks: How social production transforms markets and freedom. Yale University Press. https://doi.org/10.1177/0894439307301373

Brazil, R. (2018-08-07). Open-science hardware in the developing world. Physics World. Available at: https://physicsworld.com/a/open-science-hardware-in $\%$ e2\%80\%afthe-developing-world/

Chan, L., Okune, A., Hillyer, B., Albornoz, D., \& Posada, A. (2019). Contextualizing Openness: Situating Open 
Science. University of Ottawa Press. http://hdl.handle.net/10625/58201

Coleman, E. G., \& Golub, A. (2008). Hacker practice: Moral genres and the cultural articulation of liberalism. Anthropological Theory, 8(3), 255-277. https://doi.org/10.1177/1463499608093814

Coleman, G. (2004). The Political Agnosticism of Free and Open Source Software and the Inadvertent Politics of Contrast. Anthropological Quarterly 77(3), 507-519. doi:10.1353/anq.2004.0035.

de Brujin, E. (2010). On the viability of the Open Source Development model for the design of physical objects. Unpublished Diss.(MSc Thesis). Tilburg University. Available at: https://thesis.erikdebruijn.nl/master/Latex/thesis.pdf

Delfanti, A. (2012). Tweaking Genes in Your Garage: Biohacking between Activism and Entrepreneurship. In Sützl, W. \& Hug, T. (Eds.), Activist media and biopolitics (pp. 163-178). Innsbruck university press. Available at https://delfanti.org/wp-content/uploads/2013/05/TweakingGenes.pdf

Dosemagen, S. (2019, December 19). For a People-Centered Science: A Call to Action. Science for the People Magazine. https://magazine.scienceforthepeople.org/vol22-2/community-science-people-centered-call-action/

Fals Borda, O. (1979). Investigating reality in order to transform it: The Colombian experience. Dialectical Anthropology, 4(1), 33-55. JSTOR. Available at https://www.jstor.org/stable/29789952

Figueroa, P. M. (2013). Risk communication surrounding the Fukushima nuclear disaster: An anthropological approach. Asia Europe Journal, 11(1), 53-64. https://doi.org/10.1007/s10308-013-0343-9

Freire, P. (1973). Pedagogía del oprimido. Siglo XXI.

Fressoli, M., \& Smith, A. (2015). Impresiones 3D: Fabricación digital ¿Una nueva revolución tecnológica? Integración \& Comercio, 39, 122-125. Available at https://ri.conicet.gov.ar/handle/11336/69861

Fressoli, M., \& Arond, E. (2015). Technology for Autonomy and Resistance: The Appropriate Technology Movement in South America. STEPS Centre Working Paper 87. Brighton: STEPS Centre. Available at https://opendocs.ids.ac.uk/opendocs/handle/20.500.12413/13917

Geels, F. W. (2002). Technological transitions as evolutionary reconfiguration processes: A multi-level perspective and a case-study. 31, 1257-1274. https://doi.org/10.1016/S0048-7333(02)00062-8

Geels, F. W. (2019). Socio-technical transitions to sustainability: A review of criticisms and elaborations of the Multi-Level Perspective. Current Opinion in Environmental Sustainability, 39, 187-201. https://doi.org/10.1016/j.cosust.2019.06.009

Gibb, A. (Ed.). (2014). Building Open Source Hardware: DIY Manufacturing for Hackers and Makers. O'Reilly Media, Inc.

Glaser, B. G., \& Strauss, A. L. (1967). The Discovery of Grounded Theory: Strategies for Qualitative Research. Aldine Publishing Company.

Global Open Science Hardware (GOSH) Community. (2018). GOSH Roadmap. Available at http://openhardware.science/wp-content/uploads/2017/12/GOSH-roadmap-smll.pdf

Heradio, R., Chacon, J., Vargas, H., Galan, D., Saenz, J., De La Torre, L., \& Dormido, S. (2018). Open-Source Hardware in Education: A Systematic Mapping Study. IEEE Access, 6, 72094-72103. https://doi.org/10.1109/ACCESS.2018.2881929

Hertz, G. (2011). Arduino microcontrollers and the Queen's Hamlet: Utilitarian and hedonized DIY practices in contemporary digital culture. Proceedings of the 31st Annual Conference of the Association for Computer Aided Design in Architecture (ARCADIA). Available at https://www.researchgate.net/publication/273061788_Arduino_Microcontrollers_and The Queen's_Hamlet Ut ilitarian_and_Hedonized_DIY_Practices_in_Contemporary_Electronic_Culture 
Hess, D. (2005). Technology and Product-Oriented Movements: Approximating Social Movement Studies and STS. Science, Technology, and Human Values, 30(4), 515-535. Available at https://www.jstor.org/stable/25046621

Hess, D. (2007). Alternative Pathways in Science and industry. Activism, innovation and the environment in the era of globalization. The MIT Press.

Hylén, J. (2006). Open educational resources: Opportunities and challenges. Proceedings of open education, 4963. Available at

https://www.researchgate.net/publication/235984502_Open_educational_resources_Opportunities and challeng $\underline{\text { es }}$

Kemp, R., Schot, J., \& Hoogma, R. (1998). Regime shifts to sustainability through processes of niche formation: The approach of strategic niche management. Technology Analysis \& Strategic Management, 10(2), 175-198. https://doi.org/10.1080/09537329808524310

Kera, D. (2015). Open source hardware (OSHW) for open science in the global south: Geek diplomacy? In Open science, open issues (p. 292). IBICT. Available at http://livroaberto.ibict.br/bitstream/1/1061/1/Open\%20Science\%20open\%20issues_Digital.pdf

Kuznetsov, S., \& Paulos, E. (2010). Rise of the expert amateur: DIY projects, communities, and cultures. Proceedings of the 6th Nordic Conference on Human-Computer Interaction Extending Boundaries - NordiCHI '10, 295. https://doi.org/10.1145/1868914.1868950

Leach, M., Scoones, I., \& Stirling, A. (2010). Governing epidemics in an age of complexity: Narratives, politics and pathways to sustainability. Global Environmental Change, 20(3), 369-377. https://doi.org/10.1016/j.gloenvcha.2009.11.008

Levy, S. (1984). Hackers: Heroes of the Computer Revolution - 25th Anniversary Edition. O’Reilly Media, Inc.

Liboiron, M. (2017). Compromised Agency: The Case of BabyLegs. Engaging Science, Technology, and Society, 3, 499. https://doi.org/10.17351/ests2017.126

Maxigas, P. (2014). Hacklabs and hackerspaces: Tracing two genealogies. Journal of Peer Production. Available at http://peerproduction.net/issues/issue-2/peer-reviewed-papers/hacklabs-and-hackerspaces/

McCarthy, J. D., \& Zald, M. N. (1977). Resource Mobilization and Social Movements: A Partial Theory. American Journal of Sociology, 82(6), 1212-1241. https://doi.org/10.1086/226464

Mgbeoji, I. (2014). Global Biopiracy: Patents, Plants, and Indigenous Knowledge. UBC Press.

Murillo, L. F. R. (2018). Assembling Open Hardware at CERN. Available at SocArXiv https://doi.org/10.31235/osf.io/tqwef

Editorial: Science benefits from diversity. (2018). Nature, 558(7708), 5-5. https://doi.org/10.1038/d41586-018-05326-3

Nguyen, J. (2016). Make Magazine and the Social Reproduction of DIY Science and Technology. Cultural Politics, 12(2), 233-252. https://doi.org/10.1215/17432197-3592124

Oberschall, A. (1973). Social Conflict and Social Movements. Prentice-Hall, Inc.

Okune, A., Hillyer, R., Albornoz, D., Chan, L., \& Posada, A. (2018). Whose infrastructure? Towards inclusive and collaborative knowledge infrastructures in open science. In Connecting the Knowledge Commons-From Projects to Sustainable Infrastructure. OpenEdition Press.

Open Source Hardware Association. (n.d.). Brief History of Open Source Hardware Organizations and Definitions. Available at http://www.oshwa.org/research/brief-history-of-open-source-hardware-organizations-and-definitions/ 
Pearce, J. M. (2014). Open-source Lab. How to Build Your Own Hardware and Reduce Research Costs. Elsevier.

Pearce, J. M. (2017). Impacts of Open Source Hardware in Science and Engineering. The Bridge, National Academy of Sciences. Available at https://www.nae.edu/19579/19582/21020/174695/174822/Impacts-of-Open-Source-Hardware-in-Science-and-E ngineering

Powell, A. (2012). Democratizing production through open source knowledge: From open software to open hardware. Media, Culture \& Society, 34(6), 691-708. https://doi.org/10.1177/0163443712449497

Resnik, D. B., Elliott, K. C., \& Miller, A. K. (2015). A framework for addressing ethical issues in citizen science. Environmental Science \& Policy, 54, 475-481. https://doi.org/10.1016/j.envsci.2015.05.008

Roberts, J. T., \& Toffolon-Weiss, M. M. (2001). Chronicles from the environmental justice frontline. Cambridge University Press.

Serrano, J. (2017). Open Hardware and Collaboration. Proceedings, 11st International Workshop on Personal Computers and Particle Accelerator Controls. Available at https://doi.org/10.18429/JACoW-PCaPAC2016-THKTPLK01

Seyfang, G., \& Smith, A. (2007). Grassroots innovations for sustainable development: Towards a new research and policy agenda. Environmental Politics, 16(4), 584-603. https://doi.org/10.1080/09644010701419121

Smith, A. (2006). Green niches in sustainable development: The case of organic food in the UK. Environment and Planning C, 24(3), 439-458. https://doi.org/10.1068/c0514j

Smith et al, A. (2017). Grassroots innovation movements. Routledge.

Snow, D. A., Rochford, E. B., Worden, S. K., \& Benford, R. D. (1986). Frame Alignment Processes, Micromobilization, and Movement Participation. American Sociological Review, 51(4), 464.

https://doi.org/10.2307/2095581

Söderberg, J. (2013). How open hardware drives digital fabrication tools such as the 3D printer. Internet Policy Review,. https://doi.org/10.14763/2013.2.138

Thornberg, R. \& Charmaz, K. (2014). Grounded theory and theoretical coding. In Flick, U. The SAGE handbook of qualitative data analysis (pp. 153-169). London: SAGE Publications Ltd.

Tilly, C. (2008). Contentious Performances. Cambridge University Press.

United Church of Christ (1987). Toxic Wastes and Race in the United States: A National Report on the Racial and Socio-Economic Characteristics of Communities with Hazardous Waste Sites. New York, NY, USA.

Available at https://www.nrc.gov/docs/ML1310/ML13109A339.pdf

Visvanathan, S. (2006). Alternative Science. Theory, Culture \& Society, 23(2-3), 164-169.

https://doi.org/10.1177/026327640602300226

von Hippel, Eric. (1976). The dominant role of users in the scientific instrument innovation process. Research Policy, 5(3), 212-239. https://doi.org/10.1016/0048-7333(76)90028-7

Wylie, S. A., Jalbert, K., Dosemagen, S., \& Ratto, M. (2014). Institutions for Civic Technoscience: How Critical Making is Transforming Environmental Research. The Information Society, 30(2), 116-126. https://doi.org/10.1080/01972243.2014.875783

Wylie, S., Shapiro, N., \& Liboiron, M. (2017). Making and Doing Politics Through Grassroots Scientific Research on the Energy and Petrochemical Industries. Engaging Science, Technology, and Society, 3(0), 393-425. https://doi.org/10.17351/ests2017.134 
Submitted to the International Journal of Engineering, Social Justice \& Peace (IJESJP)

Submission date: May 2020

Review in progress 